\title{
The role of serum $\beta$-trophin and endostatin in patients with polycystic ovary syndrome: Are they correlated?
}

\author{
Wei Gong, Aikmu Bilixzi, Xinmei Wang, Yanli Lu, Li Wan and Lu Han*
}

\begin{abstract}
Background: It's necessary to investigate the serum $\beta$-trophin and endostatin (ES) level and its influencing factors in patients with newly diagnosed polycystic ovary syndrome (PCOS).

Methods: Newly diagnosed PCOS patients treated in our hospital were selected, and healthy women who took physical examination during the same period as healthy controls. We detected and compared the related serum indicators between two groups, Pearson correlation were conducted to identify the factors associated with $\beta$-trophin and $E S$, and the influencing factors of $\beta$-trophin and ES were analyzed by logistic regression.

Results: A total of 62 PCOS patients and 65 healthy controls were included. The BMI, WHI, LH, FSH, TT, FAI, FBG, FINS, HOMA-IR, TC, TG, LDL, ES in PCOS patients were significantly higher than that of healthy controls, while the SHBG and $\mathrm{HDL}$ in PCOS patients were significantly lower than that of healthy controls (all $p<0.05$ ). $\beta$-trophin was closely associated with BMI $(r=0.427)$, WHR $(r=0.504)$, FBG $(r=0.385)$, TG $(r=0.405)$ and LDL $(r=0.302$, all $p<0.05)$, and ES was closely associated with BMI $(r=0.358)$, WHR $(r=0.421)$, FBG $(r=0.343)$, TC $(r=0.319)$, TG $(r=0.404$, all $p<0.05)$. TG, BMI, WHR and FBG were the main factors affecting the serum $\beta$-trophin levels (all $p<0.05$ ). FBG, TC and BMI were the main factors affecting the serum ES levels (all $p<0.05$ ). The TG, $\beta$-trophin, ES level in PCOS patients with insulin resistance (IR) were significantly higher than that of those without IR (all $p<0.05$ ).
\end{abstract}

Conclusion: Increased $\beta$-trophin is closely associated with increased ES in patients with PCOS, which may be the useful indicators for the management of PCOS.

Keywords: $\beta$-Trophin, Endostatin, Polycystic ovary syndrome, Insulin resistance, Metabolism

\section{Background}

Polycystic ovary syndrome (PCOS) is one of the main causes of female infertility, with an incidence of about $6-12 \%$ in women of childbearing age $[1,2]$. In recent years, with the improvement of living conditions, and the changes in the living environment of human beings, the onset of PCOS has increased significantly [3]. PCOS mainly manifests as imbalance of hypothalamic pituitary

\footnotetext{
*Correspondence: mjec24@163.com

Department of Gynecology, The Fourth Affiliated Hospital of Xinjiang

Medical University, No. 116 Huanghe Road, Urumqi 214000, Xinjiang,
} China ovarian axis and metabolic disorders throughout the body. Its typical clinical features are irregular menstruation, chronic anovulation, obesity, hairiness, androgenemia, and some patients may be accompanied by metabolic abnormalities [4]. The tissue-specific Myo-inositol (MI) and D-chiro-inositol (DCI) ratio is modulated by insulin through aromatase and is altered in insulin resistance (IR), with reduced epimerization of MI to DCI in insulin-sensitive tissues [5]. It's been reported that it has been dramatically reduced by insulin-stimulated epimerase in hyperinsulinemic women with PCOS, yet the potential mechanisms remain unclear $[6,7]$. Therefore, in-depth research on the pathogenesis of PCOS is of 
great significance for improving the prognosis and quality of life of these patients.

Although the pathogenesis of PCOS is still not completely clear, IR and its compensatory hyperinsulinemia are one of its pathogenesis, and it's been reported that $70 \%$ PCOS patients have the symptoms of IR [8, 9]. $\beta$-trophin, which is secreted by the liver and adipose tissue, has been found that plays a dual role in regulating lipid metabolism and improving glucose tolerance [10]. Previous studies [11, 12] have shown that serum $\beta$-trophin levels are higher in patients with IR-related metabolic diseases (diabetes, obesity, etc.), yet the role of $\beta$-trophin in PCOS needs further investigation. In recent years, studies $[13,14]$ have shown that ovarian angiogenesis and interstitial blood flow increase in patients with PCOS, so angiogenesis disorders may be one of the main reasons for the occurrence and development of PCOS. Endostatin (ES) is an angiogenesis inhibitor, which can inhibit the proliferation of new blood vessels [15]. Previous studies $[16,17]$ have shown that the levels of ES in patients with PCOS are abnormally elevated, but the specific mechanism needs further research. Therefore, we aimed to analyze the role of $\beta$-trophin and ES in patients with PCOS, to provide the insights and evidences into the treatment of PCOS.

\section{Methods}

\section{Ethical consideration}

The ethical approvals had been obtained from the ethical committee of The Fourth Affiliated Hospital of Xinjiang Medical University (2018120609-1c), and the written informed consents had been obtained from all the included participants. All the subjects were fully informed and volunteered to participate in the study. We aimed to conduct and report this study in comply with the Strengthening the Reporting of Observational Studies in Epidemiology (STROBE) Statement.

\section{Participants}

Newly diagnosed PCOS patients treated in our hospital during December 2018 to February 2020 were selected as the study subjects. The diagnosis of PCOS was made according to the Rotterdam's criteria [18, 19]. The inclusion criteria for included patients were: (1) the age was $\geq 18$ years and $\leq 35$ years; (2) thin ovulation or anovulation; (3) clinical and biochemical manifestations of high androgens (including facial, prothoracic, and back area etc. for three consecutive months with multiple acne, hairy, seborrheic dermatitis, Total testosterone or androstenedione is higher than the normal reference value in the laboratory test); (4) polycystic changes in the ovaries are detected by ultrasound (the number of follicles with a diameter of $2-9 \mathrm{~mm}$ in one or both ovaries $\geq 12$ and/or ovarian volume $\geq 10 \mathrm{~mL}$ ). The exclusion criteria were as following: exclusion criteria: (1) patient complicated other diseases that cause elevated androgens, such as congenital adrenal hyperplasia, Cushing syndrome. And other diseases that cause ovulation disorders, such as hyperprolactinemia, abnormal thyroid function, premature ovarian failure, and pituitary or hypothalamic amenorrhea; (2) presence of moderate and severe hepatorenal dysfunction, or autoimmune disease; (3) presence of acute and chronic infectious diseases; (4) those who took hormones and other drugs that affect glucose and lipid metabolism in nearly three months.

Meanwhile, we selected healthy women who took physical examination in our hospital during the same period as healthy controls. The inclusion criteria were: (1) the menstrual cycle was regular and normal (28-35 days); (2) no clinical and biochemical manifestations of high androgen; (3) no polycystic ovarian changes were found under ultrasound detection.

\section{Data collection}

The personal information such as the date of birth, menarche age, menstrual cycle, the time of menstruation disorder began, and the beginning time of hair change. At the same time, we measured the height $(\mathrm{m})$, body weight $(\mathrm{kg})$, and waist and hip circumference $(\mathrm{cm})$. We calculated the body mass index (BMI) and waist to hip (WHR), and $\mathrm{WHR}=$ waist/hip circumference.

\section{Biochemical analysis}

We collected $5 \mathrm{ml}$ blood from the elbow vein on an empty stomach in the early morning (at least $8 \mathrm{~h}$ of fasting) from all participants. All blood samples were kept at room temperature for $30 \mathrm{~min}$, and then centrifuged at $4000 \mathrm{r} / \mathrm{min}$ for $10 \mathrm{~min}$. Then the serum was collected and stored in a refrigerator at $-80{ }^{\circ} \mathrm{C}$. Following indicators were analyzed in our laboratory: fasting blood glucose (FBG), fasting insulin (FINS), luteinizing hormone $(\mathrm{LH})$, follicle stimulating hormone (FSH), total testostrone (TT), androstendion (AND), sex hormone-binding globulin (SHBG), total cholesterol (TC), triglyceride (TG), high-density lipoprotein (high-ddensity lipoprotein (HDL), low-density lipoprotein (HDL). Besides, we calculated the homeostatic model assessment insulin resistance $($ HOMA-IR): HOMA-IR $=($ FBG $\times$ FINS $) / 22.5$. Free testosterone index $(\mathrm{FAI})=$ total testosterone $(\mathrm{TT}) /$ SHBG $\times 100$.

Enzyme-linked immunosorbent assays (ELISA) kits (Shengmin, Hangzhou) were used to determine the serum $\beta$-trophin and ES level. All the operating procedures were performed strictly in accordance with the instructions. 


\section{Statistical methods}

This present study used SPSS 23. 0 statistical software for data analysis. The data conforms to the normal distribution and the variance is expressed by $\bar{\chi} \pm \mathrm{s}$, otherwise it was expressed by M (P25, P75) and compared by log conversion to a normal distribution. $\mathrm{T}$ tests were conducted for comparing two independent samples. The relationship between variables was analyzed by Pearson correlation, and the influencing factors of $\beta$-trophin and ES were analyzed by logistic regression. The differences were considered as statistically significant if the $p<0.05$.

\section{Results}

The characteristics of included participants

A total of 62 PCOS patients and 65 healthy controls were included in this present study. As Table 1 presented, there wasn't any significant difference on the age between PCOS patients and healthy controls $(p=0.189)$. The BMI, WHI, LH, FSH, TT, FAI, FBG, FINS, HOMA-IR, TC, TG, LDL, ES in PCOS patients were significantly higher than that of healthy controls, while the SHBG and HDL in PCOS patients were significantly lower than that of healthy controls (all $p<0.05)$.

\section{The correlation analysis}

As Table 2 presented, $\beta$-trophin was closely associated with BMI $(\mathrm{r}=0.427)$, WHR $(\mathrm{r}=0.504)$, FBG $(\mathrm{r}=0.385)$, TG $(\mathrm{r}=0.405)$ and LDL $(\mathrm{r}=0.302$, all $p<0.05)$, and ES was closely associated with BMI $(r=0.358)$, WHR
Table 2 The correlation analysis among $\beta$-trophin, ES and other related indicators

\begin{tabular}{|c|c|c|c|c|}
\hline \multirow[t]{2}{*}{ Items } & \multicolumn{2}{|c|}{$\beta$-Trophin } & \multicolumn{2}{|l|}{ ES } \\
\hline & $\mathbf{R}$ & $p$ & $r$ & $p$ \\
\hline Age & 0.104 & 0.181 & 0.280 & 0.109 \\
\hline BMI & 0.427 & 0.009 & 0.358 & 0.015 \\
\hline WHR & 0.504 & 0.018 & 0.421 & 0.033 \\
\hline $\mathrm{LH}$ & 0.118 & 0.094 & 0.038 & 0.299 \\
\hline FSH & 0.206 & 0.059 & 0.332 & 0.095 \\
\hline $\mathrm{TT}$ & 0.114 & 0.072 & 0.024 & 0.081 \\
\hline SHBG & 0.121 & 0.090 & 0.137 & 0.075 \\
\hline $\mathrm{FAl}$ & 0.299 & 0.207 & 0.260 & 0.130 \\
\hline AND & 0.087 & 0.113 & 0.109 & 0.214 \\
\hline FBG & 0.385 & 0.004 & 0.343 & 0.028 \\
\hline FINS & 0.094 & 0.172 & 0.174 & 0.089 \\
\hline HOMA-IR & 0.108 & 0.089 & 0.206 & 0.057 \\
\hline $\mathrm{TC}$ & 0.142 & 0.091 & 0.319 & 0.006 \\
\hline $\mathrm{TG}$ & 0.405 & 0.011 & 0.404 & 0.014 \\
\hline $\mathrm{HDL}$ & 0.184 & 0.082 & 0.192 & 0.097 \\
\hline LDL & 0.302 & 0.042 & 0.131 & 0.082 \\
\hline
\end{tabular}

$(\mathrm{r}=0.421)$, FBG $(\mathrm{r}=0.343), \mathrm{TC}(\mathrm{r}=0.319), \mathrm{TG}(\mathrm{r}=0.404$, all $p<0.05)$.

\section{Logistic regression analysis}

Multivariate logistic regression analysis was performed with serum $\beta$-trophin as the dependent variable and

Table 1 The characteristics of included participants

\begin{tabular}{|c|c|c|c|c|}
\hline Items & PCOS group $(n=62)$ & Control group (65) & $t$ & $p$ \\
\hline Age & $25.35 \pm 3.58$ & $25.11 \pm 3.86$ & -1.032 & 0.189 \\
\hline $\mathrm{BMI}\left(\mathrm{kg} / \mathrm{m}^{2}\right)$ & $24.28 \pm 3.17$ & $21.32 \pm 3.29$ & 4.205 & 0.018 \\
\hline WHR & $0.90 \pm 0.06$ & $0.83 \pm 0.05$ & 1.127 & 0.011 \\
\hline $\mathrm{LH}(\mathrm{mlU} / \mathrm{L})$ & $9.03 \pm 1.16$ & $6.15 \pm 1.12$ & 1.184 & 0.009 \\
\hline FSH (IU/L) & $5.96 \pm 2.01$ & $9.29 \pm 2.15$ & 1.202 & 0.013 \\
\hline $\mathrm{TT}(\mathrm{nmol} / \mathrm{L})$ & $2.28 \pm 0.84$ & $1.82 \pm 0.71$ & 1.047 & 0.025 \\
\hline SHBG (nmol/L) & $32.83 \pm 9.25$ & $49.15 \pm 8.19$ & -12.184 & 0.015 \\
\hline FAl & $9.70 \pm 2.14$ & $4.52 \pm 1.18$ & 2.105 & 0.029 \\
\hline AND (ng/mL) & $3.94 \pm 1.01$ & $2.50 \pm 0.96$ & 1.146 & 0.012 \\
\hline $\mathrm{FBG}(\mathrm{mmol} / \mathrm{L})$ & $5.33 \pm 1.13$ & $4.66 \pm 1.15$ & -2.208 & 0.035 \\
\hline FINS (uIU/L) & $23.29 \pm 6.28$ & $18.14 \pm 2.24$ & 2.995 & 0.000 \\
\hline HOMA-IR & $3.92 \pm 1.14$ & $1.91 \pm 0.97$ & 1.028 & 0.007 \\
\hline $\mathrm{TC}(\mathrm{mmol} / \mathrm{L})$ & $4.86 \pm 1.65$ & $3.64 \pm 1.90$ & 1.136 & 0.015 \\
\hline $\mathrm{TG}(\mathrm{mmol} / \mathrm{L})$ & $1.43 \pm 0.84$ & $0.91 \pm 0.11$ & 1.177 & 0.023 \\
\hline $\mathrm{HDL}(\mathrm{mmol} / \mathrm{L})$ & $1.28 \pm 0.22$ & $1.32 \pm 0.18$ & 2.042 & 0.048 \\
\hline $\mathrm{LDL}(\mathrm{mmol} / \mathrm{L})$ & $2.83 \pm 0.82$ & $2.20 \pm 0.74$ & 1.192 & 0.017 \\
\hline$\beta$-trophin (pg/mL) & $145.29 \pm 30.22$ & $99.30 \pm 18.15$ & 6.695 & 0.000 \\
\hline ES $(\mu \mathrm{g} / \mathrm{L})$ & $313.09 \pm 33.15$ & $156.26 \pm 28.85$ & 20.150 & 0.000 \\
\hline
\end{tabular}


BMI, WHR, FBG, TG and LDL as independent variables. The results showed that TG, BMI, WHR and FBG were the main factors affecting the serum $\beta$-trophin levels (all $p<0.05$, Table 3 ).

Multivariate logistic regression analysis was performed with ES as the dependent variable and BMI, WHR, FBG, TC and TG as independent variables. The results showed that FBG, TC and BMI were the main factors affecting the serum ES levels (all $p<0.05$, Table 4).
The comparison on the indicators of PCOS patients with and without IR

According to the HOMA-IR, the PCOS patients were divided into IR group $(\mathrm{n}=38, \mathrm{HOMA}-\mathrm{IR} \geq 2.69)$ and a non-IR group $(\mathrm{n}=28$, HOMA-IR $<2.69)$, we have checked and adjusted the BMI and WHR for IR comparison. As Table 5 presented, the TG, $\beta$-trophin, ES level in PCOS patients with IR were significantly higher than that of those without IR (all $p<0.05$ ); There were no significant differences in age, BMI, WHI, LH, FSH,TT,FAI, SHBG, AND, FBG,FINS, HOMA-IR,TC,HDL, LDL between two groups (all $p>0.05$, Table 5).

Table 3 Logistic regression analysis on the factors related to $\beta$-trophin

\begin{tabular}{|c|c|c|c|c|c|c|}
\hline Factors & $\beta$ & $\mathbf{S} \bar{x}$ & OR & $95 \% \mathrm{Cl}$ & $p$ & Rank \\
\hline TG & 0.88 & 0.27 & 4.37 & $1.14-9.54$ & 0.012 & 1 \\
\hline BMI & 0.93 & 0.30 & 5.32 & $1.25-10.80$ & 0.030 & 2 \\
\hline WHR & 1.01 & 0.46 & 4.80 & $1.36-9.85$ & 0.041 & 3 \\
\hline FBG & 0.92 & 0.38 & 5.66 & $2.27-13.46$ & 0.028 & 4 \\
\hline
\end{tabular}

Table 4 Logistic regression analysis on the factors related to ES

\begin{tabular}{lllllll}
\hline Factors & $\boldsymbol{\beta}$ & $\mathbf{S} \overline{\mathrm{X}}$ & OR & $\mathbf{9 5 \%} \mathrm{Cl}$ & $\boldsymbol{p}$ & Rank \\
\hline FBG & 1.09 & 0.08 & 1.11 & $0.95-1.39$ & 0.009 & 1 \\
TC & 0.22 & 0.15 & 1.64 & $1.34-1.98$ & 0.016 & 2 \\
BMI & 1.19 & 0.30 & 1.16 & $0.96 \sim 1.28$ & 0.029 & 3 \\
\hline
\end{tabular}

Table 5 The comparison of collected indicators in the PCOS patients with and without insulin resistance (IR)

\begin{tabular}{|c|c|c|c|c|}
\hline Items & IR patients $(n=38)$ & No-IR patients $(n=24)$ & $\mathrm{t}$ & $p$ \\
\hline Age & $25.34 \pm 3.28$ & $25.40 \pm 3.17$ & 1.214 & 0.227 \\
\hline $\mathrm{BMI}\left(\mathrm{kg} / \mathrm{m}^{2}\right)$ & $24.49 \pm 2.24$ & $24.15 \pm 2.19$ & 3.094 & 0.024 \\
\hline WHR & $0.91 \pm 0.09$ & $0.90 \pm 0.03$ & 1.248 & 0.140 \\
\hline $\mathrm{LH}(\mathrm{m} \mid \mathrm{U} / \mathrm{L})$ & $9.10 \pm 1.29$ & $9.01 \pm 1.25$ & 1.096 & 0.226 \\
\hline FSH (IU/L) & $5.98 \pm 2.11$ & $5.96 \pm 2.04$ & 1.344 & 0.093 \\
\hline $\mathrm{TT}(\mathrm{nmol} / \mathrm{L})$ & $2.29 \pm 0.39$ & $2.27 \pm 0.35$ & 1.038 & 0.240 \\
\hline SHBG (nmol/L) & $32.94 \pm 9.44$ & $31.99 \pm 8.97$ & 3.146 & 0.054 \\
\hline FAl & $9.73 \pm 2.33$ & $9.69 \pm 3.05$ & 3.293 & 0.091 \\
\hline AND (ng/mL) & $3.95 \pm 1.14$ & $3.82 \pm 0.92$ & 1.243 & 0.225 \\
\hline $\mathrm{FBG}(\mathrm{mmol} / \mathrm{L})$ & $5.34 \pm 1.24$ & $5.28 \pm 1.26$ & 1.135 & 0.073 \\
\hline FINS (uIU/L) & $24.13 \pm 3.22$ & $23.94 \pm 2.85$ & 2.904 & 0.216 \\
\hline HOMA-IR & $2.93 \pm 1.25$ & $2.67 \pm 0.99$ & 1.811 & 0.071 \\
\hline $\mathrm{TC}(\mathrm{mmol} / \mathrm{L})$ & $4.90 \pm 1.85$ & $4.87 \pm 1.32$ & 1.203 & 0.089 \\
\hline $\mathrm{TG}(\mathrm{mmol} / \mathrm{L})$ & $1.46 \pm 0.49$ & $1.39 \pm 0.38$ & 1.285 & 0.046 \\
\hline $\mathrm{HDL}(\mathrm{mmol} / \mathrm{L})$ & $1.29 \pm 0.23$ & $1.31 \pm 0.21$ & 1.146 & 0.142 \\
\hline $\mathrm{LDL}(\mathrm{mmol} / \mathrm{L})$ & $2.85 \pm 0.83$ & $2.87 \pm 0.73$ & 1.123 & 0.317 \\
\hline$\beta$-trophin & $151.23 \pm 32.09$ & $141.29 \pm 29.05$ & 5.352 & 0.003 \\
\hline $\mathrm{ES}(\mu \mathrm{g} / \mathrm{L})$ & $319.03 \pm 32.88$ & $310.97 \pm 24.29$ & 18.135 & 0.015 \\
\hline
\end{tabular}




\section{Discussion}

Previous studies $[20,21]$ have pointed out that the incidence of PCOS in women of childbearing age ranges from 10 to $15 \%$, and it remains an increasing trend. Angiogenesis is the basis for the growth of various tissues and organs in the body, but abnormal proliferation of blood vessels can cause diseases such as tumors and cysts in the body [22]. The main motive force and nutrients of vascular hyperplasia come from the blood supply [23]. When the blood supply increases, the nutrients absorbed by the new blood vessels will increase, which will accelerate the proliferation of new blood vessels. $\beta$-trophin is one of the most critical factors regulating angiogenesis, which can promote the proliferation of vascular endothelial cells and regulate vascular permeability [24]. Studies [25, 26 ] have shown that the abnormal expression, secretion and release of $\beta$-trophin in the ovaries may be one of the pathogenesis of PCOS. ES can selectively affect the vascular endothelial cells to inhibit the growth of endothelial cells and inhibit the formation of new blood vessels [27]. Related studies [28-30] have shown that in the serum of patients with ovarian cancer, endometrial cancer, breast cancer, hepatocellular carcinoma and other tumors, the $\beta$-trophin and ES concentrations have increased significantly. However, there are very few systematic reports to date on the correlation between $\beta$-trophin, ES and PCOS. In this context, we conducted this present study to identify the role of serum $\beta$-trophin, ES expression levels in the development of PCOS, the results have indicated that both serum $\beta$-trophin, ES are closely associated with the progress of PCOS, and they are highly involved in the process of IR, both $\beta$-trophin and ES may be sensitive indicators for the development of PCOS, and they may be the effective targets for the treatment of PCOS.

The cross-talk between altered metabolic and hormonal homeostasis in PCOS women must be considered. MI and DCI have been classified as insulin-sensitizers and seem to adequately counteract several InsR-related metabolic alterations with a safe nutraceutical profile [31]. It's been reported that DCI-phosphoglycan and MI-phosphoglycan control key enzymes were involved in glucose and lipid metabolism $[32,33]$. $\beta$-trophin is a highly effective and specific pro-angiogenic factor, which acts through tyrosine kinase receptors to promote increased vascular permeability, extracellular matrix degeneration, and vascular endothelial cell migration [34, 35]. In addition, elevated levels of androgen in patients with PCOS also lead to increased levels of $\beta$-trophin secreted by ovarian cells, which in turn exacerbates vascular proliferation in these patients [36]. ES is a highly effective and specific angiogenesis inhibitor. It mainly inhibits the proliferation of vascular endothelium in PCOS patients by promoting apoptosis of endothelial cells, thereby effectively inhibiting the formation of new blood vessels in PCOS patients [37]. Interesting, this present study has also found that the levels of $\beta$-trophin and ES in the IR group were higher than those in the non-IR group, suggesting that changes in serum $\beta$-trophin and ES levels are closely related to insulin resistance in patients with PCOS. It can be explained that the insulin can aggravate the activity of vascular endothelial cells and activate the renin-angiotensin-aldosterone system, resulting in elevated serum $\beta$-trophin and ES levels in patients with PCOS.

Previous studies $[38,39]$ have shown that $\beta$-trophin is mainly expressed by liver and adipose tissue in mice and is mainly secreted by liver in humans. Animal experiments $[40,41]$ have confirmed that in mice with betatrophin overexpression, the blood TG levels have increased significantly. While in $\beta$-trophin knockout mice, the blood TG level is decreased accordingly, and lipase activity increased. It is reported that $\beta$-trophin may regulate lipid metabolism by inhibiting lipase activity [42]. It is speculated that it may be involved in lipid metabolism disorders in patients with PCOS. The results of this study have showed that the serum $\beta$-trophin of PCOS patients is positively correlated with TG, and TG is an independent influencing factor of $\beta$-trophin, which is consistent with previous findings $[43,44]$.

Several limitations in this present study should be concerned. Firstly, we selected newly diagnosed PCOS patients treated in our hospital during December 2018 to February 2020 as targeted population, we did not perform sample size calculation, the sample size was rather small, it might fail to power enough to detect the potential associations. Secondly, we only detected the related indicators in newly diagnosed patients at the very first begning, and the dynamic changes of serum $\beta$-trophin and ES cannot be reflected. Besides, the molecular ratio of ES vs. $\beta$-trophin may be more helpful to show that if this parallel rise is comparable with controls or higher in either PCOS group, due to limited data, we cannot perform analysis on this issue. In the future, the molecular ratio of ES vs. $\beta$-trophin patients at different stages of the disease should be detected to further explore its relationship with PCOS. However, the advantage of this study is that the included PCOS patients are all newly diagnosed patients without serious glucose and lipid metabolism disorders, which may avoid the effect of drugs on $\beta$-trophin and EG, so it may more accurately reflect the related indicators of PCOS patients.

\section{Conclusions}

In conclusion, the serum $\beta$-trophin and EG level in PCOS patients are higher than that of healthy people, both $\beta$-trophin and EG are closely related to PCOS. 
Furthermore, the role of $\beta$-trophin and EG may be highly associated with the glucose and lipid metabolism. Therefore, the detection of $\beta$-trophin and EG in patients' serum can be used to make the diagnostic and prognostic evaluation of PCOS. Further investigations in the future are needed to elucidate the potential mechanisms.

\section{Abbreviations}

ES: Endostatin; PCOS: Polycystic ovary syndrome; MI: Myo-inositol; DCl: D-chiro-inositol; STROBE: Strengthening the Reporting of Observational Studies in Epidemiology; IR: Insulin resistance; FBG: Fasting blood glucose; FINS: Fasting insulin; LH: Luteinizing hormone; FSH: Follicle stimulating hormone; TT: Total testostrone; AND: Androstendion; SHBG: Sex hormone-binding globulin; TC: Total cholesterol; TG: Triglyceride; HDL: High-density lipoprotein; LDL: Low-density lipoprotein; HOMA-IR: Homeostatic model assessment insulin resistance; FAl: Free testosterone index.

\section{Acknowledgements}

None.

\section{Authors' contributions}

WG, LH designed research; WG, AB, XW conducted research; WG, YL, LW analyzed data; WG and LH wrote the first draft of manuscript; LH had primary responsibility for final content. All authors read and approved the final manuscript.

\section{Funding}

None.

\section{Availability of data and materials}

Not applicable.

\section{Ethics approval and consent to participate}

The ethical approvals had been obtained from the ethical committee of the fourth affiliated hospital of xinjiang medical university (2018120609-1C), and the written informed consents had been obtained from all the included participants. All the subjects were fully informed and volunteered to participate in the study.

\section{Consent for publication}

Not applicable.

\section{Competing interests}

The authors declare that they have no competing interests.

Received: 14 April 2020 Accepted: 28 January 2021

Published online: 11 March 2021

\section{References}

1. Rondanelli M, Infantino V, Riva A, Petrangolini G, Faliva MA, Peroni G, Naso M, Nichetti M, Spadaccini D, Gasparri C, et al. Polycystic ovary syndrome management: a review of the possible amazing role of berberine. Arch Gynecol Obstet. 2020;301(1):53-60.

2. Meier RK. Polycystic ovary syndrome. Nurs Clin North Am. 2018;53(3):407-20.

3. Vatopoulou A, Tziomalos K. Management of obesity in adolescents with polycystic ovary syndrome. Expert Opin Pharmacother. 2020;21(2):207-11.

4. Sekhon AK, Zergham AS, Tserenpil G, Mebasher A, Malik BH. The association between polycystic ovary syndrome and its dermatological manifestations. Cureus. 2020;12(2):e6855.

5. Lagana AS, Garzon S, Casarin J, Franchi M, Ghezzi F. Inositol in polycystic ovary syndrome: restoring fertility through a pathophysiology-based approach. Trends Endocrinol Metab. 2018;29(11):768-80.
6. Facchinetti F, Appetecchia M, Aragona C, Bevilacqua A, Bezerra Espinola MS, Bizzarri M, D'Anna R, Dewailly D, Diamanti-Kandarakis E, Hernandez Marin I, et al. Experts' opinion on inositols in treating polycystic ovary syndrome and non-insulin dependent diabetes mellitus: a further help for human reproduction and beyond. Expert Opin Drug Metab Toxicol. 2020;16(3):255-74.

7. Facchinetti F, Unfer V, Dewailly D, Kamenov ZA, Diamanti-Kandarakis E, Lagana AS, Nestler JE, Soulage CO, Group of 'Inositol in PCOS and Reproduction. Inositols in polycystic ovary syndrome: an overview on the advances. Trends Endocrinol Metab. 2020;31(6):435-47.

8. McLuskie I, Newth A. New diagnosis of polycystic ovary syndrome. BMJ. 2017;356:i6456.

9. Hillman SC, Dale J. Polycystic ovarian syndrome: an under-recognised problem? Br J Gen Pract. 2018;68(670):244.

10. Zhang X, Chang H, Dong Z, Zhang Y, Zhao D, Ye L, Xia Q, Zhao P. Comparative proteome analysis reveals that cuticular proteins analogous to peritrophin-motif proteins are involved in the regeneration of chitin layer in the silk gland of Bombyx Mori at the molting stage. Proteomics. 2018;18(19):e1700389.

11. He J, Hu H, Dai F, Wang C. Serum levels of betatrophin in patients with newly - diagnosed polycystic ovary syndrome and its influential factors. Anhui Med J. 2018;39(2):166-70.

12. Fu Z, Berhane F, Fite A, Seyoum B, Abou-Samra AB, Zhang R. Elevated circulating lipasin/betatrophin in human type 2 diabetes and obesity. Sci Rep. 2014;4:5013.

13. Di Pietro M, Pascuali N, Parborell F, Abramovich D. Ovarian angiogenesis in polycystic ovary syndrome. Reproduction. 2018;155(5):R199-209.

14. Tal R, Seifer DB, Arici A. The emerging role of angiogenic factor dysregulation in the pathogenesis of polycystic ovarian syndrome. Semin Reprod Med. 2015;33(3):195-207.

15. Yokoyama Y, Dhanabal M, Griffioen AW, Sukhatme VP, Ramakrishnan S. Synergy between angiostatin and endostatin: inhibition of ovarian cancer growth. Cancer Res. 2000;60(8):2190-6.

16. Yokoyama Y, Sedgewick G, Ramakrishnan S. Endostatin binding to ovarian cancer cells inhibits peritoneal attachment and dissemination. Cancer Res. 2007;67(22):10813-22.

17. Wang S, Li X, Yu C, Ding H. Effects of growth hormone on the expression of vascular factors in serum and ovarian tissue of PCOS rats. Reprod Med J. 2018;27(5):444-50.

18. Rotterdam EA SPCWG. Revised 2003 consensus on diagnostic criteria and long-term health risks related to polycystic ovary syndrome. Fertil Steril. 2004;81(1):19-25.

19. Teede HJ, Misso ML, Costello MF, Dokras A, Laven J, Moran L, Piltonen T, Norman RJ, International PCOS Network. Recommendations from the international evidence-based guideline for the assessment and management of polycystic ovary syndrome. Fertil Steril. 2018;110(3):364-379.

20. Zore T, Joshi NV, Lizneva D, Azziz R. Polycystic ovarian syndrome: longterm health consequences. Semin Reprod Med. 2017;35(3):271-81.

21. Bachelot A. Polycystic ovarian syndrome: clinical and biological diagnosis. Ann Biol Clin (Paris). 2016;74(6):661-7.

22. Kopec M, Abramczyk H. Angiogenesis-a crucial step in breast cancer growth, progression and dissemination by Raman imaging. Spectrochim Acta A Mol Biomol Spectrosc. 2018;198:338-45.

23. Abramczyk H, Imiela A, Brozek-Pluska B, Kopec M, Surmacki J, Sliwinska A. Aberrant protein phosphorylation in cancer by using Raman biomarkers. Cancers (Basel). 2019;11(12):2017.

24. Cengiz M, Ozenirler S, Kocabiyik M. Serum beta-trophin level as a new marker for noninvasive assessment of nonalcoholic fatty liver disease and liver fibrosis. Eur J Gastroenterol Hepatol. 2016;28(1):57-63.

25. Yamada H, Saito T, Aoki A, Asano T, Yoshida M, Ikoma A, Kusaka I, Toyoshima H, Kakei M, Ishikawa SE. Circulating betatrophin is elevated in patients with type 1 and type 2 diabetes. Endocr J. 2015;62(5):417-21.

26. Espes D, Lau J, Carlsson PO. Increased circulating levels of betatrophin in individuals with long-standing type 1 diabetes. Diabetologia. 2014;57(1):50-3.

27. Al-Daghri NM, Rahman S, Sabico S, Amer OE, Wani K, Ansari MG, Al-Attas OS, Kumar S, Alokail MS. Circulating betatrophin in healthy control and type 2 diabetic subjects and its association with metabolic parameters. J Diabetes Complicat. 2016;30(7):1321-5. 
28. Susanto H, Liu TY, Chen CC, Purnomo JD, Chen SF, Wang CH. Increased serum levels of betatrophin in pancreatic cancer-associated diabetes. Oncotarget. 2016;7(27):42330-9.

29. Qu Q, Zhao D, Zhang F, Bao H, Yang Q. Serum betatrophin levels are increased and associated with insulin resistance in patients with polycystic ovary syndrome. J Int Med Res. 2017;45(1):193-202.

30. lizuka K. The transcription factor carbohydrate-response element-binding protein (ChREBP): a possible link between metabolic disease and cancer. Biochim Biophys Acta Mol Basis Dis. 2017;1863(2):474-85.

31. Paul C, Lagana AS, Maniglio P, Triolo O, Brady DM. Inositol's and other nutraceuticals' synergistic actions counteract insulin resistance in polycystic ovarian syndrome and metabolic syndrome: state-of-the-art and future perspectives. Gynecol Endocrinol. 2016;32(6):431-8.

32. Lagana AS, Rossetti P, Buscema M, La Vignera S, Condorelli RA, Gullo G, Granese R, Triolo O. Metabolism and ovarian function in PCOS women: a therapeutic approach with inositols. Int J Endocrinol. 2016;2016:6306410.

33. Lagana AS, Rossetti P, Sapia F, Chiofalo B, Buscema M, Valenti G, Rapisarda AMC, Vitale SG. Evidence-based and patient-oriented inositol treatment in polycystic ovary syndrome: changing the perspective of the disease. Int J Endocrinol Metab. 2017:15(1):e43695.

34. Kahraman S, Altinova AE, Yalcin MM, Gulbahar O, Arslan B, Akturk M, Cakir $\mathrm{N}$, Toruner FB. Association of serum betatrophin with fibroblast growth factor-21 in women with polycystic ovary syndrome. J Endocrinol Investig. 2018:41(9):1069-74.

35. Maurer $L$, Brachs $S$, Decker AM, Brachs $M$, Leupelt $V$, Jumpertz von Schwartzenberg R, Ernert A, Bobbert T, Krude H, Spranger J, et al. Weight loss partially restores glucose-driven betatrophin response in humans. J Clin Endocrinol Metab. 2016;101(11):4014-20.

36. Eksi Haydardedeoglu F, Bagir GS, Haydardedeoglu B, Bozkirli E, Bakiner $\mathrm{O}$, Metin K, Ertorer ME. Serum betatrophin levels are reduced in patients with full-blown polycystic ovary syndrome. Gynecol Endocrinol. 2019;35(3):224-7
37. Zhang C, Qian S, Zhang R, Guo D, Wang A, Peng Y, Peng H, Li Q, Ju Z, Geng D, et al. Endostatin as a novel prognostic biomarker in acute ischemic stroke. Atherosclerosis. 2020;293:42-8.

38. Eser Karlidag G, Arslan Solmaz O. Are adropin, apelin, elabela, asprosin and betatrophin biomarkers for chronic hepatitis and staging of fibrosis? Biotech Histochem. 2020;95(2):152-9.

39. He Y, Hu W, Yang G, Guo H, Liu H, Li L. Adipose insulin resistance and circulating betatrophin levels in women with PCOS. Biomed Res Int. 2020;2020:1253164

40. Li E, Nakata M, Shinozaki A, Yang Y, Zhang B, Yada T. Betatrophin expression is promoted in obese hyperinsulinemic type 2 but not type 1 diabetic mice. Endocr J. 2016;63(7):611-9.

41. Lu P, Chen X, Zhang Z, Zhang J, Yang Y, Liu Z, Xie J, Shao S, Zhou X, Hu S, et al. Insulin upregulates betatrophin expression via PI3K/Akt pathway. Sci Rep. 2017;7(1):5594

42. Sun LL, Liu TJ, Li L, Tang W, Zou JJ, Chen XF, Zheng JY, Jiang BG, Shi YQ. Transplantation of betatrophin-expressing adipose-derived mesenchymal stem cells induces beta-cell proliferation in diabetic mice. Int J Mol Med. 2017;39(4):936-48.

43. Calan M, Yilmaz O, Kume T, Unal Kocabas G, Yesil Senses P, Senses YM, Temur M, Gursoy Calan O. Elevated circulating levels of betatrophin are associated with polycystic ovary syndrome. Endocrine. 2016;53(1):271-9.

44. Erol O, Ozel MK, Ellidag HY, Toptas T, Derbent AU, Yilmaz N. Assessment of circulating betatrophin concentrations in lean glucose-tolerant women with polycystic ovary syndrome. J Obstet Gynaecol. 2017;37(5):633-8.

\section{Publisher's Note}

Springer Nature remains neutral with regard to jurisdictional claims in published maps and institutional affiliations.
Ready to submit your research? Choose BMC and benefit from:

- fast, convenient online submission

- thorough peer review by experienced researchers in your field

- rapid publication on acceptance

- support for research data, including large and complex data types

- gold Open Access which fosters wider collaboration and increased citations

- maximum visibility for your research: over $100 \mathrm{M}$ website views per year

At BMC, research is always in progress.

Learn more biomedcentral.com/submissions 